\title{
Sputum conversion among new smear positive pulmonary tuberculosis patients attending tb/dots clinics in Anambra state, Nigeria
}

\author{
Nwachukwu Obiora Ndubuisi ${ }^{1 *}$, Okoronkwo Christopher Uche ${ }^{1}$, Onwuchekwa Chuks Elendu ${ }^{1}$ and Valentine Nnacheta Unegbu ${ }^{2}$ \\ ${ }^{1}$ Department of Microbiology, Abia State University, Uturu,P.M.B 2000,Uturu, Nigeria \\ ${ }^{2}$ Department of Microbiology and Brewing, Nnamdi Azikiwe University Awka, Nigeria
}

\begin{abstract}
Objectives: Sputum conversion among smear-positive pulmonary tuberculosis patients was studied and its predictors evaluated in Anambra State Nigeria.The objectives were to estimate sputum conversion rates the end of 2 months following intensive treatment and also at $5^{\text {th }}$ month.

Method: Nigeria National Tuberculosis Guidelines for diagnosis of pulmonary tuberculosis was used and Acid Fast Bacilli (AFB) were determined by Ziehl-Neelsen technique. All smears with $\geq 1 \mathrm{AFB} / 100 \mathrm{hpf}$ were considered positive.

Results: A total of 183 pulmonary tuberculosis patients participated. Sputum smear conversion was observed in $159(86.9 \%)$ patients at the end of the $2^{\text {nd }}$ month. Conversion rates were $96.2 \%$ and $97.8 \%$ at end of $3^{\text {rd }}$ and $5^{\text {th }}$ months respectively. Sputum conversion rates was similar in males and females $(P>0.05)$ but age $\geq$ 45years was significantly $(\mathrm{P}<0.05)$ associated with delay in conversion. Patients with pre-treatment AFB smear grade of $3+$ had the least conversion rate than the lower grades $(\mathrm{P}<0.05)$. At the end of $5^{\text {th }}$ month, $4(2.2 \%)$ patients failed to convert.
\end{abstract}

Conclusion: Sputum smear conversion rates at end of $2^{\text {nd }}, 3^{\text {rd }}$ and $5^{\text {th }}$ months was satisfactory. Older age and initial high bacillary load were associated with delayed smear conversion.

\section{Introduction}

Pulmonary Tuberculosis (PTB) is an infectious, air-borne disease caused by various strains of Mycobacteria, especially Mycobacterium tuberculosis.It usually attacks the lungs [1]. Pulmonary tuberculosis still presents a major threat to the health of the Nigerian population. It is one of the top ten leading causes of morbidity and mortality in adult Nigerians [2].

Sputum smear examination for acid fast bacilli (AFB) during the course of treatment is an essential component of follow up studies in new smear positive pulmonary tuberculosis patients. It has been shown that regular sputum smear and culture monitoring during anti-tubercular treatment allows assessment of sputum conversion, an important issue of therapeutic planning and counseling of pulmonary tuberculosis patients [3].

When sputum smear positive tuberculosis patients are initiated on multi-drug anti-tubercular treatment, there is a multifold reduction in bacillary load expelled in sputum [4].

Examination of sputum of patients with pulmonary tuberculosis at regular intervals until conversion occurs is important for several reasons. It provides objective evidence of the patient's response to therapy.

A delayed or absent response may result from patient's noncompliance, drug resistant organisms, prescription errors, immunesuppression or mal-absorption of drugs [5].
The failure to detect these problems early and to adjust chemotherapy regimen accordingly may lead to treatment failure and potential transmission of the tubercle bacilli to others in the community [6].

The disappearance of acid fast bacilli from smears and cultures is the most widely accepted determinant for treatment of patients with pulmonary tuberculosis [7]. Patients undergo three follow-up examinations following chemotherapy in the Nigerian Tuberculosis Control Programme. It is at $2^{\text {nd }}$ or $3^{\text {rd }}, 5^{\text {th }}$ and $6^{\text {th }}$ months respectively. The $3^{\text {rd }}$ month examination is performed in the case of a positive result at the end of $2^{\text {nd }}$ month.

It is based on the high predictive value of sputum conversion on treatment that we conducted this study to estimate smear conversion at end of 2 months following intensive phase treatment and also at $5^{\text {th }}$ month afterwards.

Correspondence to: Nwachukwu Obiora Ndubuisi, Department of Microbiology, Abia State University, P.M.B 2000,Uturu. Nigeria, Tel: + 2348033561693, E-mail: nwachukwundubuisi82@yahoo.com

Key words: smear conversion, pulmonary tuberculosis, intensive phase treatment, Anambra state, Nigeria

Received: September 15, 2017; Accepted: October 20, 2017; Published: October 24,2017 


\section{Materials and methods}

\section{Study areas}

The study was carried out at two locations in Anambra State, viz Nnamdi Azikiwe University Teaching Hospital (NAUTH), Nnewi and St Charles Borromeo Hospital (SCBH), Onitsha. The former is a territory hospital while the latter is a foremost modern missionary hospital owned by Roman Catholic Mission. The TB/directly observed treatment clinicsof both hospitals handles thousands of presumptive tuberculosis cases monthly and offers free treatment to tuberculosis patients. Nnewi (located at latitude $6.03^{\circ} \mathrm{N}$ and latitude $6.92^{\circ} \mathrm{E}$ ) and Onitsha (located at latitude $6.16^{\circ} \mathrm{N}$ and longitude $6.46^{\circ} \mathrm{E}$ ) are the major industrial belts of Anambra State.

\section{Study participants}

This was a cross-sectional study involving 183 newly diagnosed pulmonary tuberculosis patients (120 patients at NAUTH,Nnewi and 63 patients at $\mathrm{SCBH}$, Onitsha). Age of the patients ranged from 15 years and older.

\section{Methods}

Diagnosis of new smear-positive pulmonary tuberculosis was based on the National Tuberculosis Guidelines. All presumptive TB cases submitted two sputum samples on the spot, within an hour interval. Smears were stained using Ziehl-Neelsen technique and acid fast bacilli graded according to the recent WHO policy change (WHO 2010a). New smear - positive pulmonary tuberculosis patients were followed up at the $2^{\text {nd }}$ and $5^{\text {th }}$ months following chemotherapy. For follow up studies, each patient submitted one sample. Data generated were analyzed using SPSS statistical software. A P-value of $<0.05$ was considered significant. The study was approved by ethical committees of both hospitals. All patients consented to participate in the study

\section{Results}

Sputum smear conversion among new smear positive pulmonary tuberculosis patients at the end of $2^{\text {nd }}$ months therapy was observed in $159(86.9 \%)$ patients. Sputum conversion rate was $87.6 \%$ in males and $85.7 \%$ in females. There was no significant difference $(\mathrm{P}>0.05)$ in smear conversion rates between males and females. Sputum smear conversion rate declined with older age. It was $25 \%$ in the 65 years age group but $100 \%$ in 15-25years class. Age was associated with delayed in sputum conversion (Table 1).

Patients with an initial pre-treatment AFB smear grade of 3+ had the lowest conversion rate $(74.6 \%)$ compared to the other smear gradings of $2+(89.8 \%)$ and $1+(100 \%)$. A significant difference $(\mathrm{P}<0.05)$ existed between initial AFB smear grading and sputum conversion. (Table 2).The sputum smear conversion at $2^{\text {nd }}, 3^{\text {rd }}$ and $5^{\text {th }}$ months post therapy showed that $104(87 \%), 115(96 \%)$ and $117(98 \%)$ patients respectively converted at Nnamdi Azikiwe Teaching Hospital, Nnewi while 55(87\%), 61(97\%) patients respectively converted at St Charles Borromeo Hospital, Onitsha. At the end of the $5^{\text {th }}$ month, however a total of 4 patients failed to convert (Figure 1).

\section{Discussion}

The best way to monitor treatment result of new smear positive pulmonary tuberculosis patient is to check for conversion of sputum from smear positive to smear negative.
In this study, sputum conversion rate among new smear positive pulmonary tuberculosis patients at the end of 2 months post therapy was $86.9 \%$. This was similar to $86.6 \%$ recorded in Cameroon [8]. Our finding was however higher than $82 \%$ observed in Rwanda [9] but lower than $98.6 \%$ observed in studies in Tanzania [10].

Sputum conversion at 2 months is associated with treatment outcome. Our result confirms that the possibility of reaching a cure was higher among patients whose sputum had converted than among those whose sputum remained positive at 2 months. In spite of the intensive treatment for 2 months, 24(13.1\%) patients remained sputum AFB positive. Epidemiological study indicated that the proportion of pulmonary tuberculosis patients who remain smear-positive after 2 months of treatment can be greater than $20 \%$ [11]. These persistently positive cases after 2 months of treatment are a predictor of patient infectivity and treatment failure [11].

Gender was not associated with sputum conversion in this study. It was a supervised treatment (directly observed treatment) and provision of free cost treatment could also be responsible for the insignificant difference observed. This finding was however different from a study among a Portuguese population [6] where male gender was associated with longer conversion time. Habits such as smoking and alcohol intake common with males might be the reason for the difference.

Delayed sputum smear conversion was observed with age older than 45years.A previous study [12] have shown that lack of smear conversion was more common in older patients. With advancing age, there may be increased delay in clearing the bacilli. This may probably be due to delay in seeking care and diagnosis which might lead to progression of the disease.

Patients with high pre-treatment grade of $3+$ had significantly lower sputum conversion. A study in Morocco [13] on factors influencing sputum conversion among sputum smear-positive pulmonary tuberculosis patients had similarly reported that high sputum AFB grades were associated with persistent AFB smear 2months after chemotherapy. Similar results were also reported in Pakistan [14]. These patients could continue to transmit tuberculosis on the community.

The sputum conversion rates in this study at $2^{\text {nd }}, 3^{\text {rd }}$ and $5^{\text {th }}$ months was $86.9 \%, 96.2 \%$ and $97.8 \%$ respectively. This was satisfactory and similar to $84 \%$ at the end of $2^{\text {nd }}$ month and $92 \%$ at the end of $3^{\text {rd }}$ month observed in India [15]. Follow-up studies thus identify cases that will benefit from a prolongation of the $2^{\text {nd }}$ month intensive treatment.

Treatment failed in only 4 patients (i.e. they failed to convert after 5 months of chemotherapy). These four patients are presumptive multidrug resistant TB cases. They were referred to GeneXpert MTB/RIF test and culture. However, the use of treatment supporters at home would help tuberculosis patients to adhere to treatment.

In conclusion, sputum conversion among new smear positive pulmonary tuberculosis patients at the end of 2 months treatment was $86.9 \%$.Older age ( $\geq 45$ years) and higher bacillary load were associated with delayed smear conversion while gender was not.

\section{Limitation}

Smear microscopy was the only diagnostic procedure employed in the study. It is not sensitive in patients with low bacterial load. The gold standard - Mycobacterial culture was not available. 


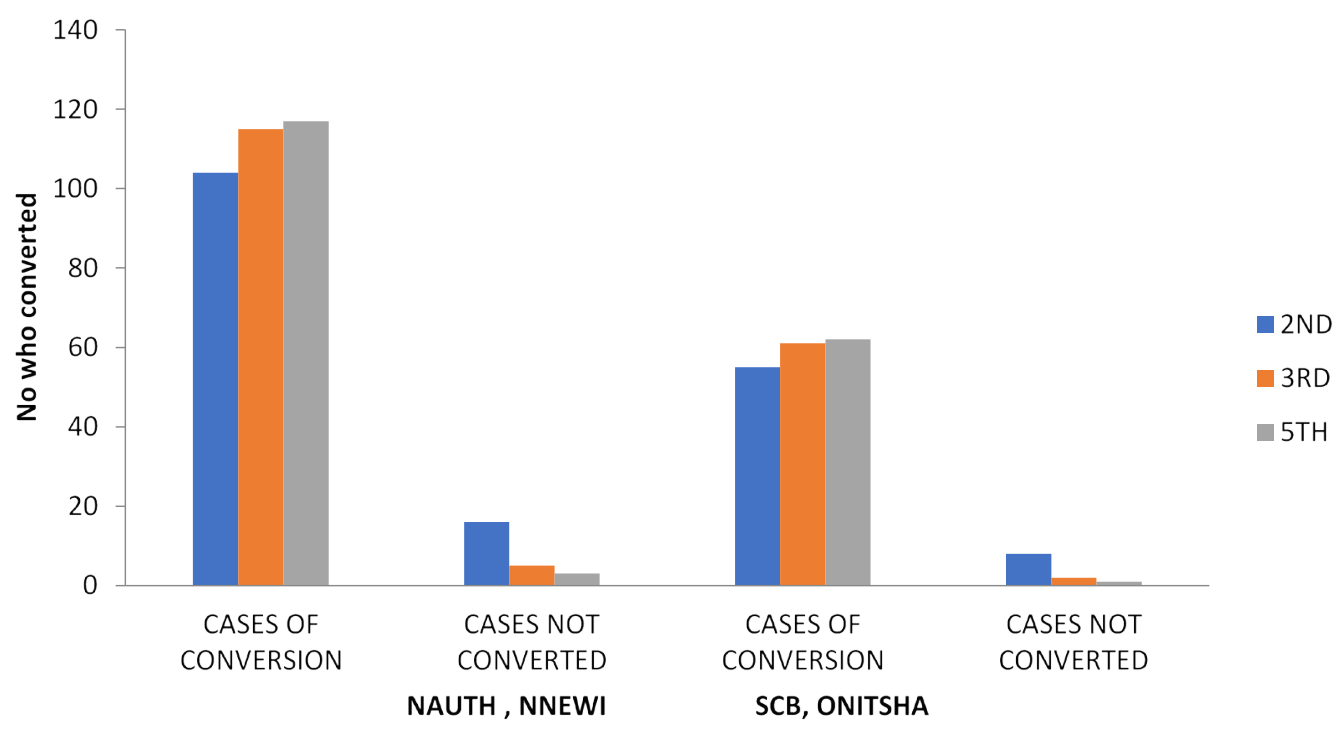

Figure 1. Sputum smear conversion at $2^{\text {nd }}, 3^{\text {rd }}$ and $5^{\text {th }}$ months at NAUTH, Nnewi and SCB, Onitsha.

Table 1. Sputum conversion among new smear positive PTB patients at the end of 2 months treatment at NAUTH, Nnewi and SCBH, Onitsha

\begin{tabular}{|c|c|c|c|c|c|c|c|}
\hline $\begin{array}{c}\text { Age } \\
\text { group (yr) }\end{array}$ & M+ & $\mathbf{F}+$ & $\mathbf{T}+$ & MC (\%) & FC (\%) & TC (\%) & TNC (\%) \\
\hline $15-24$ & 17 & 8 & 25 & $17(100)$ & $8(100)$ & $25(100)$ & $0(0)$ \\
\hline $25-34$ & 41 & 30 & 71 & $40(97.6)$ & $29(96.7)$ & $69(97.2)$ & $2(2.8)$ \\
\hline $35-44$ & 26 & 21 & 47 & $25(96.2)$ & $19(90.3)$ & $44(93.6)$ & $4(6.4)$ \\
\hline $45-54$ & 17 & 6 & 23 & $12(70.6)$ & $3(50.0)$ & $15(65.2)$ & $8(34.8)$ \\
\hline $55-64$ & 9 & 4 & 13 & $4(44.4)$ & $1(25.0)$ & $5(38.5)$ & $8(61.5)$ \\
\hline $65 \&$ above & 3 & 1 & 4 & 1(33.3) & $0(0)$ & $1(25.0)$ & $3(75.0)$ \\
\hline Total & 113 & 70 & 183 & $99(87.6)$ & $60(85.7)$ & $159(86.9)$ & $24(13.1)$ \\
\hline
\end{tabular}

M+: Males AFB positive; F+: Female AFB positive; T+: Total AFB Positive; MC: Males who converted; FC: Females who converted; TC: Total conversion; TNC: Total non conversion

Table 2. Sputum smear conversion according to bacillary load at end of 2 months treatment at NAUTH, Nnewi and SCBH, Onitsha

\begin{tabular}{|c|c|c|c|}
\hline $\begin{array}{c}\text { Pre-treatment } \\
\text { AFB grading }\end{array}$ & $\begin{array}{c}\text { No positive } \\
\text { of cases } \\
(\mathbf{n = 1 8 3})\end{array}$ & $\begin{array}{c}\text { Cases who } \\
\text { converted (\%) }\end{array}$ & $\begin{array}{c}\text { Cases not } \\
\text { converted (\%) }\end{array}$ \\
\hline $3+$ & 71 & $53(74.6)$ & $18(25.4)$ \\
\hline $2+$ & 59 & $53(89.9)$ & $6(10.2)$ \\
\hline $1+$ & 30 & $30(100)$ & $0(0)$ \\
\hline Scanty & 23 & $23(100)$ & $0(0)$ \\
\hline Total & 183 & $159(86.9)$ & $24(13.1)$ \\
\hline
\end{tabular}

$\mathrm{P}>0.05$ (two-way ANOVA)

\section{References}

1. World Health Organisation (2013) Factsheet $N^{O} 104$ updated Oct $6^{\text {th }} 2013$, Geneva.

2. National Tuberculosis and Leprosy Control Programme. Annual Report. 2013. Abuja, Nigeria.

3. Horne DJ, Royce SE, Gooze L, Naritq M., Hopewell PC, et al. (2010) Sputum monitoring during tuberculosis treatment for predicting outcome: systematic review and meta-analysis. Lancet Infect Dis 10: 387-394. [Crossref]

4. Parikh R, Gita N, Swapna K, Vijah K, Preeri M (2012) Time to sputum conversion in smear positive pulmonary tuberculosis patients on Cat I DOTS and factors delaying it. JAPI 60: 22-26. [Crossref]

5. Su WJ, Feng JY, Chin YC(2010) Role of 2-months sputum smears in predicting culture conversion in pulmonary tuberculosis. Eur Respir J 37: 376-383. [Crossref]

6. Mota C, Carvalho A, Valente I, Braga R, Duarte R(2012) Predictors of delayed sputum smear and culture conversion among a Portuguese population with pulmonary tuberculosis. Rev Port Pneumol 18: 72-79. [Crossref]

7. World Health Organization (2010) Framework for implementing new tuberculosis diagnosis 2010; Geneva, Switzerland.
8. Kuaban C, Bame R, Monanague L, Djella S, Omgni C (2009) Non-conversion of sputum smear-positive pulmonary tuberculosis patients in Yaounde, Cameroon. East Afr Med J 86: 216-225. [Crossref]

9. Felix RK, Mirjam IB, Veronical M, Michael G, Maarten FSL (2012) Sputum completion and conversion rates after intensive phase of tuberculosis treatment: an assessment of the Rwandan control Programme. BMC Research Notes 5: 357. [Crossref]

10. Senkoro M, Mfinaga SG, Morkve O (2010) Smear microscopy and culture conversion rates among smear positive pulmonary tuberculosis patients by HIV status in Dare Salam Tanzania. BMC Infect Dis 10: 210. [Crossref]

11. Wang JY, Lee LN, Yu CJ, Chien YJ, Yang PC (2009) Factors influencing to smear conversion in patients with smear-positive pulmonary tuberculosis. Respirology 14 1012-1019. [Crossref]

12. Patra S, Lukhmana S, Smith TK, Kannan AT, Satyanarayana S, et al. (2013) Profile and treatment of elderly patients with tuberculosis in Delhi, India: implications for their management. Trans R Soc Trop Med Hyg 107: 763-768. [Crossref]

13. Khalid B, Mohammed A, Karima M, Monna S, Rachida Z, et al. (2013) Factors influencing sputum pulmonary tuberculosis patients in Morocco. ISRN Pulmonary ID486507.

14. Unsemathan S, Kateruttanakul P (2013) Factors predicting sputum smear conversion and treatment outcomes in new smear-positive pulmonary tuberculosis patients. $J \mathrm{Med}$ Assoc Thai 96: 644-649. [Crossref]

15. Bawn S, Ali S, Phukan C, Layal B, Baruwa P (2008) A study of sputum conversion in new smear positive pulmonary tuberculosis cases at the monthly intervals of $1^{\text {st }}, 2^{\text {nd }}$ and $3^{\text {rd }}$ month under directly observed treatment short course (DOTS) regimen. Lung India 25:118-112. [Crossref]

Copyright: (C2017 Ndubuisi NO. This is an open-access article distributed under the terms of the Creative Commons Attribution License, which permits unrestricted use, distribution, and reproduction in any medium, provided the original author and source are credited. 